\title{
Research on Curriculum Construction of Universities of Applied Science
}

\author{
Liu Wenhua \\ Institute of Higher Technical Education, Shanghai Dianji University, \\ 1350 Ganlan Rd., Pudong New District, Shanghai, China \\ Iwhuajky@163.com
}

\begin{abstract}
Key words: Technical Undergraduate Education, Curriculum Construction, Technical Route Abstract. Universities of applied Science have been pilot project in China. Their unique value and core elements give expression to the curriculum. Judging from the current situation, there are lots of problems in their curriculum. The curriculum construction should base on their special requirements and their own attribute. The curriculum construction of universities of applied science can develop through the management, the organization, the technology and the assurance.
\end{abstract}

\section{The Problems of Curriculum of Universities of Applied Science and Their Attributions}

The Problems of Curriculum of Universities of Applied Science.The decision of striving to develop universities of Applied Science is new things in China's policies. So there must be many problems in their curriculum construction.

For most of programs of universities of applied science, their talents cultivating plan, curriculum contents, textbook, teaching methods are mostly the same with research universities. As a unique sort of undergraduate education, universities of applied science must have their curriculum system, which is the supporting condition to make them as a unique one type of education.

This problem can be seen from the textbook. As we know, most textbook in China's universities, academic departments decide which textbook they want to buy uniformly. The decision is mainly affected by the program leaders. The program leaders would like to choose the textbooks from their own academic underground. The mechanism of choosing textbooks determines the theorization of curriculum content. Only very few of teachers would like to develop school-based textbooks. Some universities of applied science maybe set a few of experimental lessons and training courses so as to embody the character of technology applications. But in essence, curriculum contents don't get fundamental changes. There are no obvious differences between universities of applied science and research universities in curriculum contents.

Talents cultivating standards are the programmatic documents of higher education and vocational education. Talents cultivating standards are worked out by the Specialty Establishment Committee. The Specialty Establishment Committee is made up of leaders of departments, leader of program, faculties, enterprises' personnel etc. In the process of working out talents cultivating standards, the persons who play the decisive role are those leaders of program and faculties who have academic background.

The Attributions of the Current Problems in Curriculum of Universities of Applied Science. Although the curriculum construction of vocational education has been taken seriously nationwide, we still do not pay enough attention to the curriculum construction which is the core mission of vocational education. The curriculum construction is often put on the back burner when it compare with school-running model and quality assurance and so on. Some most of universities of applied science, scientific research is still the priority.

As what mentioned before, the methods and processes of developing talents cultivating standards of universities of applied science have no obvious differences with that of research universities. In fact, the curriculum developing methods of universities of applied science have their particular characters and logic. So it is necessary to research how to explore the unique curriculum development methods of universities of applied science from nationwide level to program administrators, faculties and curriculum experts' levels. 
Those experimental universities of universities of applied science are mostly newly-promoted undergraduate colleges. These colleges expand rapidly in recruiting new teachers. Lots of graduates with PHD degree from research universities hold the post of teachers in universities of applied science. These new teachers don't know the students' learning situation so well, and they have less experience of teaching so they are not good at choosing curriculum contents, teaching design, classroom management and curriculum assessment.

\section{The Requirements from Curriculum Construction of Undergraduate Education of Applied Science}

Higher character and Technicality. The reason why technical undergraduate education can be particular type of education is that the talents it cultivates are irreplaceable. Then what kinds of talents that universities of applied science should cultivate? The talents type is advanced technical talents. On the basis of the theory of talents classification, talents types can be divided into four types: science-oriented talents, engineering talents, technical talents and skilled talents. Among them, engineering talents can be divided into three type: engineering theory talents, engineering design talents and engineering implementing talents. The primary mission of universities of applied science is to cultivating engineering design talents. The subordination mission of universities of applied science is to cultivating engineering implementing talents.

The talents cultivating orientation determines that technical undergraduate education has two features: higher character and technicality. The higher character is to compare with higher vocational education. Technicality is to compare with research undergraduate education.

Firstly, the curriculum contents should embody the higher character. Comparing with secondary vocational education and higher vocational education, the knowledge level and capability requirements to students of curriculum contents should be higher level. We can see it from Fig. 1.

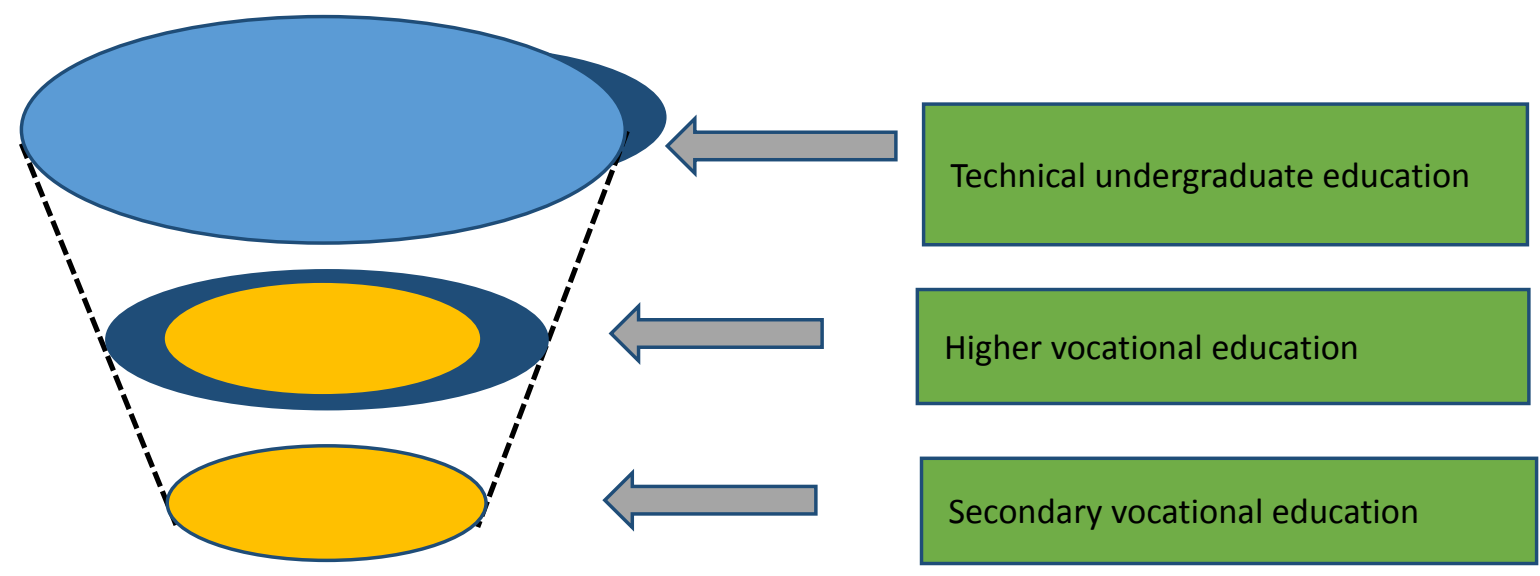

Fig. 1. Comparison among three types of education

From Fig. 1, the curriculum contents' level of technical undergraduate education is higher than secondary vocational education and higher vocational education. The relationship between these three types of education is like a bowl.

Secondly, the curriculum organization of technical undergraduate education should embody technicality. Though the curriculum contents' level of technical undergraduate education is higher than secondary vocational education and higher vocational education, the curriculum contents among them is not simply overlay. Technical logic should be considered. So the concrete implement of curriculum aim and contents of technical undergraduate education should technical factor analysis of professional positions. 
Discipline and Professionalism. As what mentioned before, the curriculum contents' level of technical undergraduate education is higher than secondary vocational education and higher vocational education. The higher level reflects in the depth, integrity and system of knowledge, not in the quantity of knowledge. The depth, integrity and system of knowledge should be implemented into discipline construction. Some scholars ever suggest that universities of applied science do not need carry out discipline construction. They think academic research is not important nor necessary. So in their opinion program construction is more important than discipline construction. But in fact, this is a shortsighted view, even a prejudice. Academic research is the second mission of universities. If universities of applies science do not carry out academic research, the knowledge system of curriculum contents will be not integrated, and the teaching ability of teachers will reduce their effectiveness.

So the question is not if universities of applied science need academic research but what kind of academic research universities of applied science need. In fact, academic research is very necessary to universities of applied science. What kind of academic research it need is applied research, especially focusing on engineering and technology. Universities of applied science do not need to carry out pure theoretical research.

\section{The Strategies of Curriculum Construction of Universities of Applied Science}

Curriculum is the key factors that can influence mission's realization and social influence. So if we want to realize the uniqueness of technical undergraduate education as a particular type of higher education, its curriculum must be deepen. For many years, the reason why technical undergraduate education often get lots of criticism is its curriculum do not embody its mission and vision. So we should strengthen the importance of curriculum construction of universities of applied science. The administrators should consider to work out some specific policies.

The curriculum construction of technical undergraduate education refer to many organizations and people. So the curriculum construction should be scientifically organized so as to harmonize all involved many organizations and people to work together. As a new-born thing, the curriculum construction of technical undergraduate education need forceful leadership and administration. Therefore, we recommend that the nationwide steering committee of curriculum construction should be set up. The committee takes charge of policy making, technical route development, personnel organization, results assessment, and so on.

The curriculum construction of technical undergraduate education not only need concept changing and policies making but also technical route and methods. Because it is a brand-new curriculum which is different with traditional ternary form of curriculum. At present, the main problem which the curriculum construction of technical undergraduate education is facing is it is strongly affected by traditional curriculum concept. To solve this problem, we can take example by learning from international curriculum development theory and technical route. On the basis of this, the curriculum construction of technical undergraduate education launch to explore Chinese vulgar technical route of curriculum development.

\section{References}

[1] Guoqing Xu: The Rational Thinking About the Curriculum's status of Vocational Education: the View of Macropolicy. Education Research, 2013, No. 10, pp.13. In Chinese.

[2] Liang Xu: Philosophy of Technology. Fudan University Press, 2005, pp.76. In Chinese.

[3] Guoqing Xu: The Connotation of Technical Undergraduate Education. Jiangsu Higher Education, 2014, No. 6, pp.11-14. In Chinese.

[4] Jianguo Xia: The Introduction of Technical Education at the undergraduate level, Oriental Press Center, 2008 No.10, pp. 4. In Chinese. 
[5] D. Archorena and F. Caillods, Technical Education: a dead or adopting to change, UNESCO International Bureau of Education and Academic Publishers, 1999, pp. 97-102. 